\title{
Introduction to modern art font variant design in the application of
}

\section{cultural industry brand promotion}

\author{
Ping Leng \\ Harbin University of Science and Technology Rongcheng Campus, Rongcheng 264300, China.
} 474288172@qq.com

Keywords: Modern art font variant design, Cultural brand, Cultural elements, Brand promotion, Chinese traditional culture.

\begin{abstract}
In today's society, the development of cultural and artistic activities is increasingly important to people. Not only to meet the growing demand of the people, but also to meet the constant pursuit of spiritual. Especially in the construction of spiritual civilization, the relationship between art development and carry forward the national culture is very close. Font variant of modern art plays an important role in cultural branding, we not only need to think about the font-variant design of modern art in cultural branding construction and development, and fully study the importance of the integration between the font variants of modern art design and the national culture, as well as an exploration of font variant design of modern art into the cultural background. Chinese characters as the basic elements of Chinese character design play a major role.
\end{abstract}

\section{The Introduction}

1. The background of the study. Font variant of modern art design is one of the basic elements of companies and culture brand identity system, widely used, commonly associated with logo together, has a clear accountability, conveys the business or brand to the audience directly, passes information synchronized with the visual and auditory, and strengthens corporate image and brand appeal, the importance of design has the same importance as the logo.

2. The significance of the research. Font-variant of modern art design promoting brand and culture is for human societies or groups even as the cultural identity of peoples and nations, the continuation of national spirit, plays a very important role. In the contemporary world to enhance "cultural diversity" and "respect for human creativity" as the common ideas, protection of the intangible cultural heritage of humanity has been unprecedented attention. The protection of intangible cultural heritage requires vigorous promotion of cultural branding to let the masses to percept and pass on their own national culture.

\section{Font variant designs is an important means of brand VI design concept to convey}

1. Fonts designs is the most basic element of corporate identity system. In the day more than competitive on the global market, font-variant design of modern art provides us with a more effective more clarity and more friendly of cultural brand and corporate image. And thus font design becomes the most basic elements of the corporate identity system. Variant font is the form of a visual expression of information in the long life and practice, and can make people understand the meaning of certain words. It has simple, clear, straightforward visual transfer. Font-variant design involves psychology, aesthetics, colors, etc. Refined, abstracted and processed in practice, in a way 
of typical font forms and express a certain spirit, communicates specific information, forms a visual language to communicate with each other.

2. Font variant design services for the brand culture image (MI) design. By giving the brand deep and rich cultural connotations, brand culture image builds up its brand positioning, making full use of font design transmission can cultivate consumer's brand identity and brand beliefs, eventually forms a strong sense of brand loyalty. Loyalty to the brand will be able to win customer loyalty, win a stable market, greatly enhance the competitiveness of enterprises, and provide a powerful guarantee for the successful implementation of the brand strategy.

Font design represents the entire brand culture evolvement, represents the interests cognitive of businesses and consumers and emotional closeness, is the sum of the traditional culture and personality of the brand image.

\section{Necessity of the modernization of traditional culture}

In China, the Chinese culture itself is a social phenomenon, is the product creating for a long time. But it is also a historical phenomenon, is the accumulation of social history. In the cultural brand, modernization of traditional culture is the most important aspect, which is in essence on the basis of cultural innovation, traditional culture keeps up with the pulse of the times and achieves the modernization of traditional culture also strongly highlights the brand identity of Chinese traditional culture.

\section{The font variant design of a cultural industry brand design}

Font variant design, as the media characteristics in cultural brand promotion, in order to implement all visual recognition functions in the most effective space, usually combines cultural brand element pattern with the special characters which can express the cultural brand feature, to show the identified on description, communication, communication to guide the audience's interest, enhance the reputation, easy to memory, etc.

Form combinations are generally divided into cultural brand pattern, cultural brand text and synthetic text.

1. Cultural brand design. Culture brand symbol has a characteristic of unique, eye-catching, pattern itself vulnerable to distinguish, the memory. By association, generalization and abstract painting performance method, and correlation with the identified body is not directly, audience easily memory pattern itself, but on the relationship between the culture brand of cognitive need relatively tortuous process, but once established, are impressive, a relatively permanent memory to culture brand.

2. Cultural brand text. In communication and dissemination activities, repeated use of culture brand name or the product name, unified in a written form. Clear and direct meaning, with close links to the cultural brand, easy to be understood and cognized, also has the description on the concept of role.

3. Synthetic text. It's a synthesis of graphics and text which refers to the text and pattern design, owing the properties of words and designs, but relatively weaken the influence of relevant properties, making partial pattern variant design, can make people more profound to the culture brand memory. 


\section{The importance of the typeface aberration design in the traditional culture image remoulding process}

1. Information transmission. The writing in the visual transmission, as one of picture vivid essential factors, has the transmission sentiment function, thus it must have the visual esthetic sense, can give the human esthetic feeling. Meeting people's esthetic need and enhancing the beautiful taste is each designer's responsibility. In the writing design, the beauty is not manifested merely in partial, but is to have the entire assurance of the Chinese character standard shape, the structure and the entire design, The character is a shape combined with horizontal, vertical, spots, circular arc and other lines, in the structure arrangement and in line matching, in the structure arrangement and line matching, how to coordinate the character and the character, the stroke and the stroke, emphasizing the rhythm and the rhythm, to create design with a richer expressive force and the power, and convey the content accurately and distinctively to the audience, is important topic of the writing design.

2. Injecting modernity. Fonts designed inject the modernity into traditional culture, plays an important role in the whole process of a nation's survival and development, the modernity in the modern traditional culture plays an important role for every national culture, it is the embodiment of national spirit. The Chinese nation have formed powerful vitality of traditional culture in creating human civilization of process in the, injecting modern culture elements in traditional culture not only reflect noble national spirit, national integrity, and cover philosophy, social sciences, and science, culture art and many fields, and this can make traditional culture adapt contemporary development, dig traditional culture resources in today culture, has important realistic and historic significance for flourishing the modern traditional culture .

\section{VIThe layout design principles of Font-variant design}

\section{Font design.}

(1) Changing font structure

The structure is the typeface constitution principle, using what principle to set up the typeface, and using what to form the individuality characteristic of the typeface in the typeface constitution, all need to be solved by the structure. In the typeface constitution, the transformation of structure is the main technique of manifesting the typeface creativity performance. The structure transformation must be based on the existing typeface structure rule, creates each kind of new structures through the creative change and the transformation

(2) Chinese character shape of Transformation typeface

A typeface shape cannot change in terms of some regulated typeface, the Song typeface is constituted by a set of Song typeface standard shape, the blackbody is constituted by a set of black pen shape, but to the creative individual, may carry on the transformation according to the different creativity source, through all sorts of transformation technique processing, can often bring the new and distinctive style.

(3) Putting the representative elements

In typeface structure full utilize image to change original structure style, joining the design element, can from unprecedented individuality in the typeface constitution substantive characteristics. Either using abstract linear to change partial stroke of the structure, either using the Succinct explains righteousness image to borrow some one side stroke, either using some kind of image or some image to constitute mutually dependent image, all can through the different techniques of image superimposition to mold new typeface structure style. 
(4) Breakthrough typeface contour

Regardless of the Chinese character or the Latin typeface, basing on the deference typeface overall contour standard, you can choose one or two strokes to breakthrough contour limits, either outward extends, connected, or contracting, relying other strokes, next you can also use the expressing subjects needs to change the $\mathrm{c}$ the typeface into various inorganic shape. The breakthrough typeface contour performance must consciously jump out the original convention definition, and change typeface overall image trend from flexible angle, make the typeface overall image unfold the different intrinsic vigor and the visual impulse.

2. Graphic language expression. A cultural brand has its own unique pattern cultural elements, the cultural element pattern will often be the simple representative and reflect their brand. Cultural element pattern is the culture accumulation formed by cultural brand, and represents the brand and consumers' interests awareness, emotional closeness, and is the sum of traditional culture and personality brand image, the cultural element highlights the enterprise external publicity advantages and integration advantages, make culture brand effectively pass on to the customer, then occupied the minds of consumers. Then the cultural elements have an important representational role of the brand.

Adding the brand cultural element pattern to the font-variant design of modern art, to conduct change decoration and processing. Its characteristic is get rid of the constraint of print styleand the stroke to some extent, to design according to the cultural brand management needs, to achieve the objective of strengthening the spiritual meaning of the text and appealing effects.

For example: The Chinese tradition acrobatics Peking opera cultural element is styles of makeup. Seeing the styles of makeup, people first think of the Peking opera, thus the makeup styles element has represented the Peking opera culture brand. Regardless of is or propagandizes or the cognition, the styles of makeup held the pivotal status and the function in the Peking opera culture.

\section{Conclusion}

Using the cultural element to design the typeface aberration and remould the cultural image have the good initiative function for the people to enhance the cultural accomplishment and the traditional culture inheritance. Therefore, the typeface aberration design integrating the cultural brand element greatly raise the modern people's cultural inheritance consciousness. The typeface aberration design based on "the cultural element", has better manifested ancient artistic and the traditional culture merit, and the value of worth the current people's study, have inherited and carried forward the nationality traditional culture, manifested broad and profound cultural, and has the good initiative function to the people's manner and the feeling of facing the life.

\section{References}

[1] Zehou Li, Ji Liu. Aesthetics of China [M]. Anhui literature and art publishing house, 1999.

[2] Jie He. Modern font design art [M]. Hebei fine arts publishing house, 1992102-105.

[3] Shouzhi Wang. The world history of graphic design [M]. China youth press, 2002.9.

[4] Jielian Liao. Chinese font creator [M]. Central China science and technology press, 2012.9.

[5] Yanzai Yuan. In the design of design [J]. Journal of shandong people's publishing house, 2006.11.1. 